\title{
Child Drawing: A Projective Tool for Dental Anxiety Assessment
}

INTRODUCTION: Assessment of child's anxiety is important in order to determine the success of dental treatment. Drawing, a nonverbal, self-report, projective and non-invasive technique may prove be helpful and needs to be explored in order to access anxiety in children requiring dental treatment.

AIM: To investigate the applicability of children's drawings as an indicator to measure their level of anxiety.

MATERIALS \& METHOD: A cross-sectional study was conducted in a total of hundred children between age group of 4-6 years. Children were asked to draw dental operatory on $\mathrm{A}_{4}$ sheet and colour it with basic set of 12 colours. The drawing was scored using Child Drawing: Hospital (projective scale) scale and the results were compared with pulse oximeter readings (physiological parameter) and Venham Picture Test scorings.

RESULTS: Child Drawing: Hospital scale scoring had a positive correlation with pulse oximeter reading (involuntary) ( $\mathrm{p}$-value = 0.125 ) and a negative correlation with Venham picture test ( $\mathrm{p}$-value $=0.140$ ).

CONCLUSION: Drawing may be statistically significant projective tool significant to assess child anxiety in dental setting.

KEYWORDS: Anxiety, Drawing, Psychology

\section{INTRODUCTION}

Monitoring and assessment of anxiety are indispensable to build a positive dental attitude in children in order to deliver effective dental services. The terms "anxiety" and "fear" are inter-related with fear being one of the many variables that contribute to heightened levels of anxiety whereas, anxiety is an excessive and unreasonable negative emotional state, the source of which is ambiguous, unclear, or not immediately present. ${ }^{1}$ Anxiety hinders children's coping ability, causes behavioural changes, and encourages negative emotional behavior. ${ }^{2}$

Anxiety is a subjective component that bring about the physiological change in body which could be measured using pulse oximeter, a non-invasive technique. It helps in real-time recording of physiological parameters such as blood pressure, pulse rate, oxygen saturation, and body temperature. ${ }^{3}$

Motivating interventions such as information, relaxation, and cognitive coping strategies given preoperatively can minimize children's pre- and postoperative anxiety and increase their cooperation. The ideal measure should be valid, allow for limited cognitive and linguistic skills, and be easy to administer and score in a clinical context. Venham Picture Test
(VPT) is one of the few picture scales that covers all these criteria. However, anxiety scales range in complexity, sensitivity and reliability. Projective techniques are used to measure anxiety which encourage hidden emotions of child to be projected on to a non-threatening object. Drawing is one such projective technique that is used to measure anxiety in a fun way. ${ }^{4-7}$

Drawing facilitates children's abilities to talk, particularly about those events or concepts they might otherwise find difficult to describe. Unlike other assessment procedures, such as psychometric tests, drawing requires little or no training. For many children, drawing represents a natural activity that is spontaneously and frequently participated in, usually with much enjoyment. Therefore, when applied in the clinical dentistry settings it is likely to reduce the child's anxiety about the situation and the nature of the treatment. $^{8}$

Tracing the history of this method, human figure drawings as assessment tools, have been widely used since as early as the 1920 s by Goodenough and later by Koppitz PT et al. to estimate children's expectations of an ideal hospital. In 1999, Child Drawing: Hospital 
(CD:H) scale was developed as a means of measuring the anxiety of hospitalized school-age children. In the field of dentistry, Pond DA (1968) found stories concerned with pain, blood and other signs of aggression in a series of children's drawings collected by a dentist. Sheskin RB et al. (1982) utilized drawings of children in a dental setting as an assessment tool for their anxiety. ${ }^{9}$

This study aims to investigate the applicability of children's drawings as an indicator to measure their level of anxiety compared to pulse oximeter and VPT scale in the dental setting and hence apply for effective and precalculated child behaviour management techniques.

\section{MATERIALS AND METHODS}

The present cross-sectional study was carried out over a period of 3 months (August-September 2019) in children who visited the OPD of Department of Paediatric and Preventive Dentistry, within the specified time period. After initial examination, over 300 children were initially recruited. However, 100 children who fulfilled the inclusion criteria and whose parents gave the consent were included in the study.

Inclusion and Exclusion criteria: Children between the age group of 4-6 years who were visiting the department for the first time and required restorative treatment, with complete physical and mental health without any confounding medical history were included. However, children who reported with acute pain that required emergency dental treatment or children suffering from any illness requiring special medical care and who were not interested in drawing were excluded from the study.

Scales used: Three different scales were used in the present study:

1. Pulse oximeter: for measuring the physiological changes like heat rate.

2. Venham Picture (Figure 1): It consists of eight cards with pictures of children in various dental situations. There are two figures on each card, one in which a child appears non-anxious and the other one in which he looks anxious. Each child was asked how they would feel about visiting the dentist and to point out the figure they liked the most. A score of 1 was given for every anxious figure selected and o for every non-anxious figure selected. So, a child could score a maximum of 8 scores and a minimum of o. A score of 4 or more was considered to be above average anxious score.

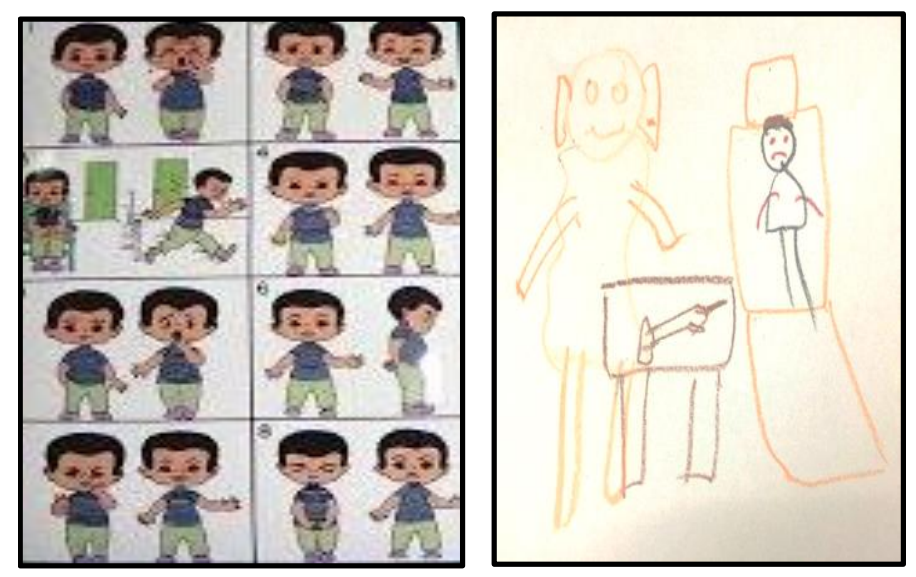

Figure 1. Venham Picture Test (left) and CD:H score interpretation on a child's drawing (right):

Part A: Lying on chair(8), Standing grounded(1), Frown(9), Smiling(1), Colour prominence-Orange(6), No. of colours used: 4(6)Placement of paper-centre(1),Quality of strokes: medium, equal light \& dark(5), large \& threatening(10).

Part B: Omission-feet \& palm, exaggeration: ear, eye, mouth

3. Drawing Method and assessment method: Children were then instructed to draw a picture of the dental operatory in their own understanding. The scoring of which was carried out according to $\mathrm{CD}: \mathrm{H}$ Scoring Guide and Rating Scale and the CD:H score sheet. The scoring of drawing is divided into three sections. Part A which contains 14 items: position, action, length, width, and size of a person; eyes and facial expressions, colour predominance, numbers of colours used, use of the paper, placement on the paper, stroke quality, inclusion and size of dental equipment and developmental level. Each item is scored on a scale of 1-10, with 1 indicating the lowest level of anxiety and 10 the highest. [Figure 1 (Part A \& B), Annexure 1]

Part B consists of eight items indicating pathological indices. The omission, exaggeration, and de-emphasis of a body part receive five points. Distortion, the omission of two or more body parts, transparency, mixed profile, and shading receive 10 points. If each of these items is not present, a score of o is recorded. Part $C$ is a response by the scorer to the child's anxiety as expressed in the picture on a 1-10 scale. A score of 1 indicates coping or low anxiety and a score of 10 
indicates disturbance or high anxiety. The total score is determined by adding the totals of parts A, B and C. Level of anxiety based on the total score obtained from the $\mathrm{CD}: \mathrm{H}$ score sheet was as follows: $\leq 43$ : very low stress, 44-83: low stress, 84-129: average stress, 130-167: above average; and 168 and over: very high stress. (Table 1)

\begin{tabular}{|c|c|}
\hline \multicolumn{1}{|c|}{ SCORE } & STRESS LEVEL \\
\hline$\leq 43$ & Very low stress \\
\hline $44^{-83}$ & Low stress \\
\hline $\mathbf{8 4 ^ { - 1 2 9 }}$ & $\begin{array}{c}\text { Average stress } \\
\text { Above average }\end{array}$ \\
\hline $130-167$ & Very high stress \\
\hline 168 and over & \\
\hline Table 1. Interpretation of CD:H Scoring \\
\hline
\end{tabular}

The children who fulfilled the inclusion criteria were then subjected to three scales where in the first appointment before the start of the treatment the children were made to sit on dental chair and pulse oximeter was applied. The readings were recorded at regular intervals. While the children still in the dental chair, children were given set of Venham picture test cards and were asked to score their anxiety level accordingly. Later on, after the treatment they were made to sit in waiting room and instructed to draw a picture of the dental operatory in their own understanding. The children were given a blank $\mathrm{A}_{4}$ sheet of paper and a box of twelve basic colours. Parents were allowed to be with them during their drawings. However, the objective of the study was described for the parents and they were instructed not to influence the child respond in any way. There was no time restrictions and the drawings were collected once the child has completed.

\section{RESULTS}

A total of 100 children (50 male and 50 females) participated in the study. In the present study, anxiety of children was first observed with pulse oximeter. Reading of 110 and above indicated child to be anxious whereas reading between 70-110 indicated non-anxious child. Based on the reading criteria 26 children were non-anxious and 74 children were anxious. On basis of sex of the child, males showed more anxiety with mean pulse oximeter reading of $124.66 \pm 15.29$ as compared to females $120.78 \pm 16.1$. However, no statistical difference was observed between them p-value was 0.187 (Figure 2). The pulse oximeter readings indicated that $74 \%$ of children were already anxious about their dental treatment as they entered the operatory.

The mean VPT score for children with 4 or more score indicated anxiety. For females whereas mean score was 3.9, it was higher for males 4.3 (Figure 3).

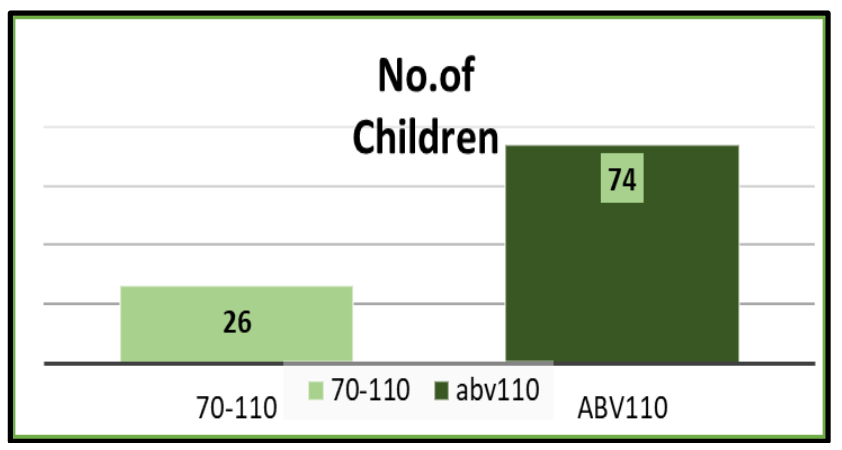

Figure 2. Number of children showing above 110 pulse oximeter reading. ABV: Above

However, on statistical analysis using Chi-square test no significant difference was observed ( $\mathrm{p}$ value 0.45 ). This value indicates that though the difference was not significant but half the number of children were anxious before the treatment owing to the figures, they selected from the VPT cards.

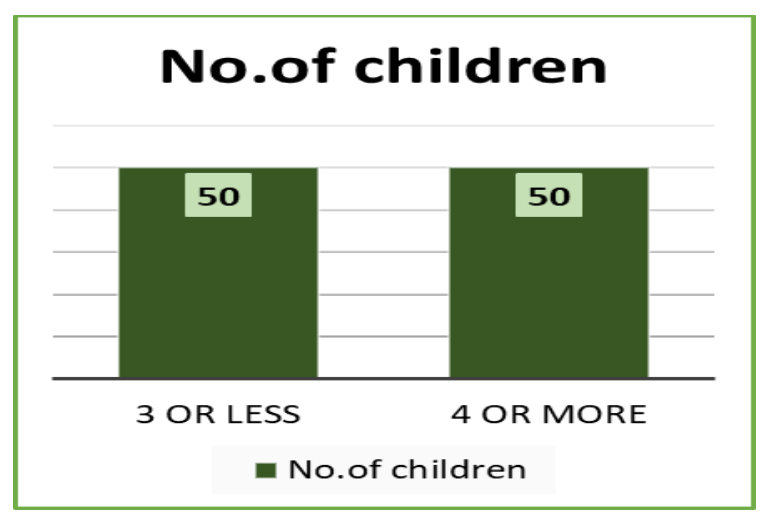

Figure 3. Number of children showing 4 or more VPT Score. VPT: Venham Picture Test

On evaluating the drawings, out of 100 children, 84 children (38-females and 46-males) had above average anxiety and 16 children (12-females and 4-males) had anxiety (Figure 4). Chi square value calculated was 4.762 and $p$ value was significant $(<0.029)$. On basis of 


\begin{tabular}{|c|c|c|c|}
\hline & \multicolumn{1}{c}{ Pulse Oximeter Reading } & \multicolumn{2}{c|}{ VPT Score } \\
\hline Gender & Mean \pm SD & Mean \pm SD & Mean \pm SD \\
\hline Female & $120.78 \pm 16.15$ & $3.9 \pm 1.33$ & $140.26 \pm 15.36$ \\
\hline Male & $124.66 \pm 15.29$ & $4.3 \pm .2$ & $143.68 \pm 13.27$ \\
\hline
\end{tabular}

Table 2. Mean \pm SD score for all three scales according to gender. VPT: Venham Picture Test, CD:H: Child Drawing: Hospital Score

gender, mean CD:H score was $140.26 \pm 15.36$ for females and $143.68 \pm 13.27$ for males with above average anxiety (table 3). The Chi square value calculated was 38.45 and $\mathrm{p}$ value was 0.168 (not significant). The interpretation of the drawings revel that about $84 \%$ of children had stress indicators in their drawing indicating their above average anxiety level.

There was a negative correlation between VPT and pulse oximeter (-o.140), however, a positive correlation was seen between $\mathrm{CD}: \mathrm{H}$ score and pulse oximeter(0.125) which implies that $\mathrm{CD}: \mathrm{H}$ scores are closely associated with physiological parameters i.e. pulse oximeter readings which indicates a relatively comparative anxiety level between both the methods. As the pulse oximeter readings correlates with the physiological parameters like heat rate, blood pressure and respiratory rate, its was considered as a control and its correlation values with the $\mathrm{CD}: \mathrm{H}$ scale implies that drawing provides a positive medium to indicate the relevant anxiety level of a child (Table 3 ).

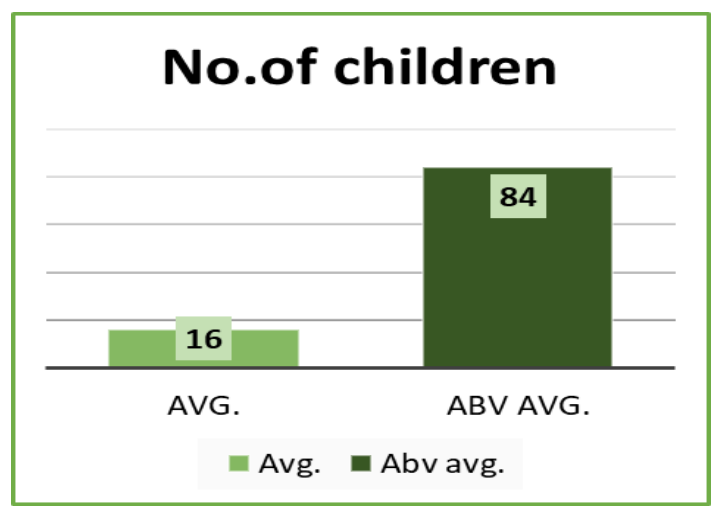

Figure 4. Child Drawing: Hospital Scale-Number of children showing above average score (130-167) AVG: Average, ABV: Above

\section{DISCUSSION}

Age has been cited as a determining factor in the contest to anxiety as its seen that younger children display more anxiety than older children.1 This could be explained by Paget's theory of cognitive development where an increase in anxiety in children aged between 3 and 6 years is cited as they are in the preoperational stage of development and are not able to think logically. They focus on magical thinking and are less able to distinguish reality from fantasy. As children get older and enter into the concrete operational stage, their cognitive abilities mature. The logical progression may enable children to develop coping behaviours to help deal with the stress thereby reducing anxiety. ${ }^{10}$

In the present study pulse rate was used as a reliable indicator to evaluate anxiety level in children. It was used as an objective measure of dental anxiety and it was seen that the mean reading for both the genders was above 110 which indicates an increased level of anxiety in the youngest age group evaluated. The physiological change in the body such as an increase in perspiration, breathing rate, blood pressure, heart rate, and pulse rate, which is primarily due to the release of stress hormones in the blood such as cortisol, adrenaline, and nor-epinephrine could be recorded by the pulse oximeter.,"11 According to the study by Rosenberg and Katcher et al. (1976) the anxiety provoking situations alter the physiological functions like Pulse Rate and Blood Pressure.12 The increase in Pulse Rate and Blood Pressure can be used to assess dental anxiety in children. Studies by Messer JG et al. $(1977)^{13}$ and Beck FM et al. (1981) ${ }^{14}$ confirmed that the physiological changes occur in the body as a result of the stress suffered by patients during dental procedures and these physiological changes are very useful for measuring anxiety level in a patient before and after the dental treatment. ${ }^{15}$ 


\begin{tabular}{|c|c|c|c|c|}
\hline & Mean & SD & Correlation & Sig \\
\hline $\begin{array}{l}\text { VPT } \\
\text { PO }\end{array}$ & $\begin{array}{c}4.44 \\
127.66\end{array}$ & $\begin{array}{l}0.760 \\
8.898\end{array}$ & -0.140 & 0.331 \\
\hline $\begin{array}{c}\text { CD:H } \\
\text { PO }\end{array}$ & $\begin{array}{l}146.58 \\
127.34\end{array}$ & $\begin{array}{l}9 \cdot 546 \\
9 \cdot 317\end{array}$ & 0.125 & 0.290 \\
\hline
\end{tabular}

Table 3. Correlation between VPT, CD: H and Pulse oximeter. VPT: Venham Picture Test, CD:H: Child Drawing: Hospital Score

Venham picture test was given by Venham 1979, it is one of the few picture scales that fulfills the required criteria to assess dental anxiety in children, which assesses how negative the child feels. In our study though the number of anxious and non-anxious children were equal the mean value for anxious males (4.3) was comparatively more than females (3.9). When the anxiety rating scores were compared for gender differences, significant differences were not found in the present study. However, some studies have reported higher anxiety for girls but this was not found in our study, where boys were more anxious than girl. ${ }^{16}$ To understand a child's internal psychological state projective testing is one strategy that may be use. This strategy is designed to allow the child to respond openly to an ambiguous stimulus to reveal internal conflicts and subconscious distress. ${ }^{17}$

Drawing can be used in any setting and for many purposes, such as diagnosis, assessment, research, or the measurement of progress in therapy. It is used as an art therapy and represents a phenomenological approach. It is visual imagery of how children see the world in both its simplicities and its complexities. It is used as projective technique for assessing children's inner world, emotions and interpersonal styles. According to this approach, drawing is not a spontaneous action but rather an intentional process involving projection and introjections by the children. This process can help children express themselves in ways that verbal language cannot and can provide helpful information on their emotional attitudes and well-being. ${ }^{18}$

In the present study, a statistically significant $\mathrm{CD}: \mathrm{H}$ score of the 4-6 year-old children was noticed, which probably indicates an increased level of anxiety in the youngest age group. In fact, for children of 4-6 years of age, drawing can facilitate discussions about traumatic experiences by providing a link between children's internal thoughts and their perceived reality, by which the young children seek to express themselves and their experiences. ${ }^{19}$

The results of our study are in accordance with the result of Clatworthy $S$ et al., who found children's drawing in hospital is a valuable assessment tool to measure the emotional status of hospitalized children. $^{20}$

According to Mathur J et al. (2017) children requiring specialized behavioral techniques can be identified by the presence of stress markers in their drawings. This nonverbal activity by itself can have an overall positive effect on the behavior displayed in the dental clinic. ${ }^{21}$

Drawing has a large significant effect on children's reports about their presenting problems. The opportunity to draw not only increases the amount of clinically relevant information that children reported, but it also has a positive effect on the overall interaction of the child with the dentist. ${ }^{22}$

\section{CONCLUSIONS}

Drawing can be used as an efficient tool for determining level of the dental anxiety in young patients. It is easier, familiar and correlates with the physiological parameters.

Limitation of the study: It is time-consuming and does not correlate with other projective scales like VPT, however, better results could be achieved with larger sample size and due to its exploratory nature, further studies are advised.

\section{REFERENCES:}

1. Tunney AM, Boore J. The effectiveness of a storybook in lessening anxiety in children undergoing tonsillectomy and adenoidectomy in Northern Ireland. Issues in comprehensive pediatric nursing 2013;36(4):319-35.

2. Li HC, Chung OK. The relationship between children's locus of control and their anticipatory anxiety. Public Health Nursing 2009;26(2):153-60.

3. Tiwari N, Tiwari S, Thakur R, Agrawal N, Shashikiran ND, Singla S. Evaluation of treatment related fear using a newly developed fear scale for children: "Fear assessment picture scale" and its association with 
physiological response. Contemporary clinical dentistry 2015;6(3):327-31.

4. Venham LL, Gaulin-Kremer E. A self-report measure of situational anxiety for young children. Pediatr Dent. 1979;1(2):91-6.

5. Brennan A. Caring for children during procedures: a review of the literature. Pediatric nursing. 1994;20(5):451-8.

6. Ellerton ML, Merriam C. Preparing children and families psychologically for day surgery: an evaluation. Journal of Advanced Nursing 1994;19(6):1057-62.

7. Ziegler DB, Prior MM. Preparation for surgery and adjustment to hospitalization. The Nursing Clinics of North America 1994;29(4):655-69.

8. Driessnack M. Children's drawings as facilitators of communication: a meta-analysis. Journal of Pediatric Nursing. 2005;20(6):415-23.

9. Aminabadi NA, Ghoreishizadeh A, Ghoreishizadeh

M, Oskouei SG. Can drawing be considered a projective measure for children's distress in paediatric dentistry?. International journal of paediatric dentistry. 2011;21(1):12.

10. Brewer S, Gleditsch SL, Syblik D, Tietjens ME, Vacik HW. Pediatric anxiety: child life intervention in day surgery. Journal of pediatric nursing 2006;21(1):13-22. 11. Sridhar S, Suprabha BS, Shenoy R, Shwetha KT, Rao A. Effect of a relaxation training exercise on behaviour, anxiety, and pain during buccal infiltration anaesthesia in children: Randomized clinical trial. International journal of paediatric dentistry 2019;29(5):596-602.

12. Rosenberg HM, Katcher AH. Heart rate and physical activity of children during dental treatment. Journal of dental research 1976;55(4):648-51.

13. Messer JG. Stress in dental patients undergoing routine procedures. Journal of dental research 1977;56(4):362-7.
14. Beck FM, Weaver JM. Blood pressure and heart rate responses to anticipated high-stress dental treatment. Journal of dental research. 1981 Jan;6o(1):26-9.

15. Khokhar V, Gupta B, Kaur J. Evaluation of Anxiety Level of Children Aged 6 - 9 Years During Sequential Dental Visits Using Objective and Subjective Measures. EC Dental Science 2017;15(4):93-103.

16. Krishnappa S, Srinath S, Vishwanath SK, Bhardwaj $P$, Singh R. Evaluation of facial image scale and Venham picture test used to assess dental anxiety in children. Journal of Indian Association of Public Health Dentistry 2013;11(3):31-5.

17. Hatano Y, Yamada M, Nakagawa K, Nanri H, Kawase $M$, Fukui K. Using drawing tests to explore the multidimensional psychological aspects of children with cancer. Japanese journal of clinical oncology 2014;44(10):1009-12.

18. Hamama L, Alshech M. Children with epilepsy: assessing state anxiety through drawings and a selfreport questionnaire. Arts \& health 2018 Oct 19:1-5.

19. Stafstrom CE, Rostasy K, Minster A. The usefulness of children's drawings in the diagnosis of headache. Pediatrics. 2002;109(3):460-72.

20. Clatworthy S, Simon K, Tiedeman ME. Child drawing: Hospital-An instrument designed to measure the emotional status of hospitalized schoolaged children. Journal of Pediatric Nursing 1999;14(1):29.

21. Mathur J, Diwanji A, Sarvaiya B, Sharma D. Identifying dental anxiety in children's drawings and correlating it with frankl's behavior rating scale. International journal of clinical pediatric dentistry 2017;10(1):24-8. doi: 10.5005/jp-journals-10005-1401.

22. Woolford J, Patterson T, Macleod E, Hobbs L, Hayne H. Drawing helps children to talk about their presenting problems during a mental health assessment. Clinical child psychology and psychiatry 2015;20(1):68-83. 
ANNEXURE 1: CD:H Scoring sheet

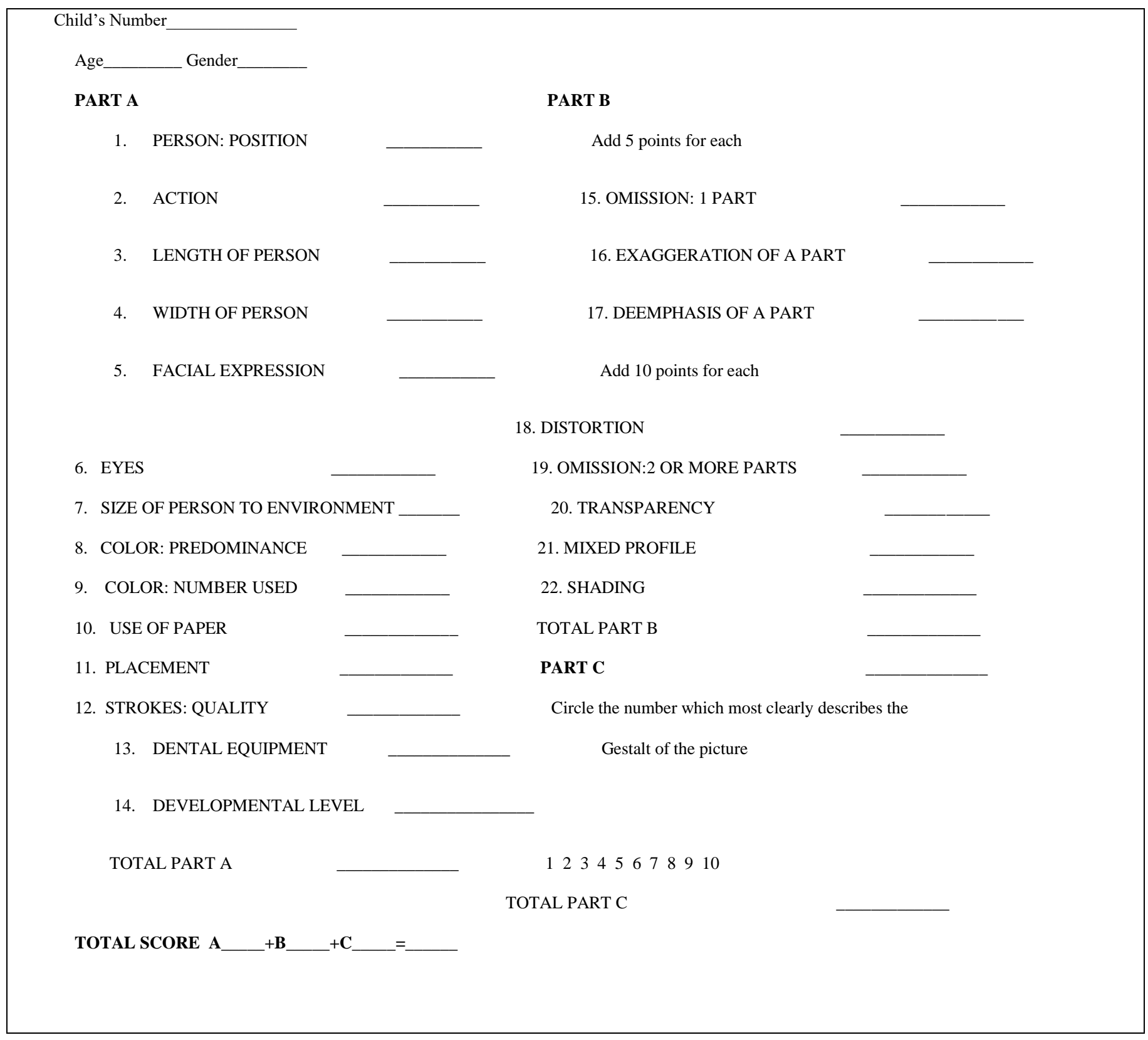

